urethra. At panendoscopy the haricot bean, which had begun to sprout, was removed in three parts (fig 2) with a combination of long artery forceps and cystoscopic biopsy forceps. The patient was catheterised and given a course of broad spectrum antibiotics until the penile oedema and induration had resolved. His diuretic treatment was stopped.

At follow up two months later he was asymptomatic and no longer suffered from urinary incontinence. Uroflowmetry showed no evidence of a urethral stricture, and he was discharged.

\section{Discussion}

Urinary incontinence, especially as a sequel to treatment with diuretics, remains a troublesome symptom in elderly men and often causes both dismay and embarrassment. When surgical or drug treatment is not appropriate a variety of continence aids, ranging from the penile clamp to the condom catheter, can be used. None of these devices are, however, free of complications.

Maintaining continence with a dry haricot bean placed just within the external urethral meatus is a novel and ingenious concept based on the ball valve stopcock principle, and this case shows that it is effective. But this new continence aid is not without potential hazard, especially in the unwary elderly patient with compromised vision or poor manual dexterity. Although psychosexual disorders in young men are often associated with introducing a foreign body into the urethra or bladder, 'there is no evidence to support this premise in elderly men.

Bichler KH. Foreign body injuries of urethra and bladder in the young: their psychosexual background. Urol Int 1971;26:161-70.

\title{
Natural history of the disappearance of various products in the course of the transfer from socialist economy to regulated market
}

\section{G E Falkowski}

This study was undertaken to assess certain common features in the disappearance of various products and goods from the general commodity circulation (GCC). This particular period (summer and autumn 1990), 45 years after the end of the second world war, is called by the government "the period of transfer to regulated market economy."

\section{Material and methods}

The study is based on observations of the situation in Moscow (population over 7 million) during eight consecutive months of 1990 (January to August). The methods used included the five known human senses: sight, hearing, smell, taste, and touch. The sixth sense,

\section{"I am happy to have lived my life in order to prove someone else's theory" - $\mathrm{M}$ ZHVANETSKY.}

also known as common sense, was applied in various situations that intermittently appeared in the course of observation. In some instances the seventh sense, so called intuition, also had to be used, but it rarely helped. All the animals observed did not receive human care whereas the human subjects were treated according to principles of laboratory animal care formulated by the National Society for Medical Research and the guide to the care and use of laboratory animals prepared by the National Academy of Sciences and published by the National Institutes of Health (NIH publication No 80-23, revised 1978).

Student's $t$ test for paired values, the non-parametric Mann-Whitney test, univariate regression analysis with the two tailed Fisher's exact test, and $\chi^{2}$ analysis were all used in order to obtain maximum objectivity.

Bakulev Institute of Cardiovascular Surgery, Moscow

G E Falkowski, MD, professor of paediatric cardiovascular surgery

BrMed J 1990;301:1433-4
III); partial absence of item (stage IV); total absence (stage $\mathrm{V})$.

\section{STAGE I: RUMOURS}

This stage starts with a colleague or neighbour mentioning casually that a certain item is absent in the GCC. The phase might begin with the words "they say" or "I was told" (difference between words: statistically negligible). The statement can concern either the direct absence of the item or the possibility of a twofold or threefold increase in its price, in which case it begins with the same words but more commonly includes the phrases "I have heard" or "Did you watch TV last night?" The crucial question that may arise during this phase, "Who are 'they'?" can never be answered and certainly should be investigated further.

The most characteristic feature during this particular period of observation is that no matter how illogical and absurd the stage I might have seemed it invariably led to stage II. The time difference between the stages depended mostly on the susceptibility of the subjects and lasted from a few hours to several days, depending on the product or item in question. The difference was not statistically significant $(\mathrm{p}>0 \cdot 2)$.

\section{STAGE II: QUEUES}

This feature, which is also known in international literature as "lines," has always been extremely characteristic of Russian society. In previous years queues were mostly sporadic, chaotic, inexplicable, or seasonal. They also occurred in other countries, even in the so called developed countries. As an example of a non-parametric queue we joined in a line in New York City as a matter of habit. Using this habitual approach, based on a decades old principle that includes getting into the line first and finding out what the people are standing for afterwards, we learned that this line led to an art gallery featuring an exhibition of Picasso's works; hence it was distinguishable from the queues of stage II as being mostly of a spiritual nature.

The Russian queues we studied were without exception material $(\mathrm{p}<0.00001)$. They could be observed at 6 am outside a shop that opens at $9 \mathrm{am}$, at which point they resembled a many tailed monster. Some lines were almost invisible, but at the entrance to the shop several serious looking individuals with lists in their hands could be seen. This meant that this particular line was 
Stages in process of disappearance reached by selected products and goods in general commodity circulation at

\begin{tabular}{ll}
\hline Item & Stage \\
\hline Bread & IV-I* \\
Vodka & III-IV \\
Wine & V \\
Cheese & II-V \\
Butter & III \\
Sugar & V \\
Gasoline & II-IV \\
Soap & V-II^ \\
Tobacco & V \\
Taxis & IV-V \\
\hline
\end{tabular}

Stage $\mathrm{I}=$ rumours; stage $\mathrm{II}=$ queues; stage III = multiple purchase (when available); stage

IV=partial absence; stage $V=$ total absence.

absence. period of observation and then went back to beginning of cycle. fItem strictly rationed. September 1990

organised, had its own committee, and lasted for days or even weeks. Each participant had a certain number and once or twice a day had to be present in person at a prescribed hour to confirm his or her resolve to remain in the line until the bitter end. In case of absence the participant's name was struck off the list without any voting (Queue International, Joint Venture. Manual of Procedure. In press).

The psychology of a queue is a subject of special research (grant No 1917-1990). The variables depend mostly on the item to be purchased (for example, sugar, vodka, visa to Israel, men's underwear, ladies' shoes, bread, cigarettes, etc). In brief, features common to any queue might be summarised as: anxiety, moderate aggressiveness, solidarity, and melancholy humour. These can develop rapidly into severe aggressiveness and even hostility towards the administration, the government, the Communist Party and its former and contemporary leaders, the queue committee, or towards other members of the queue, in which case the level of solidarity and humour simultaneously decreases $(\mathrm{p}<0.005)$.

\section{STAGE III: MULTIPLE PURCHASE}

During this stage, which invariably follows stage II, the subjects tend to purchase the item in question in much greater quantities than before stages I and II (for example, five loaves of bread, two pairs of socks, a hundred litres of gasoline, etc). Consequent limitations might simultaneously be set, often initiated or provoked by the members of the queue, who shout "Do not give more than. . . to. [one pair of hands]!" (a very specific, untranslatable expression meaning one subject). If the reaction of the administration is delayed, the volume of individual purchase depends, obviously, on the financial possibilities of the subject, as well as on the sixth and seventh senses already mentioned, and takes into account the number of relatives, friends, as well as acquaintances on whom the next needed item might depend.

\section{STAGE IV: LIMITED ABSENCE}

This stage runs parallel to stage III, sometimes overlapping it in time. During this period one observes that an item is absent in the usual places or at the usual shopping time, being present in other places that are still undergoing stages II and III. One of the specific features of this stage is complete closure of the "selling spots" (shops, gas stations, etc) for indefinite repairs that can last for ages or for ever.

\section{STAGE V: TOTAL ABSENCE}

The complete disappearance of the indications of the previously described stages means nowadays that the

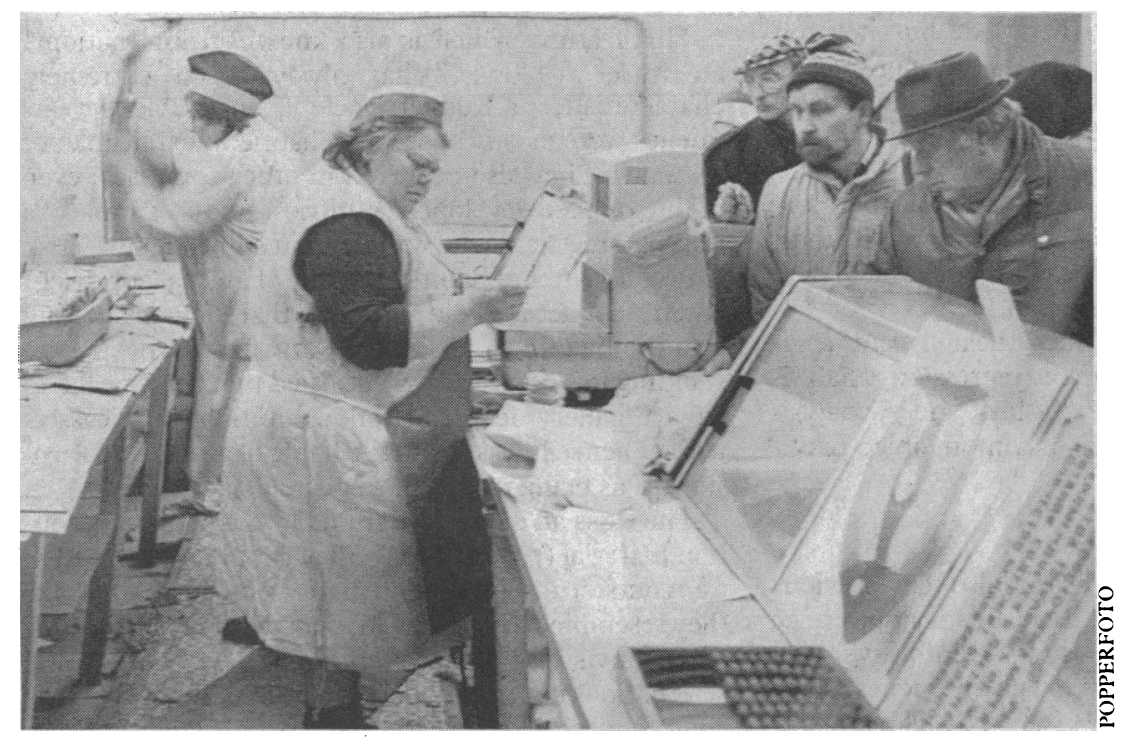

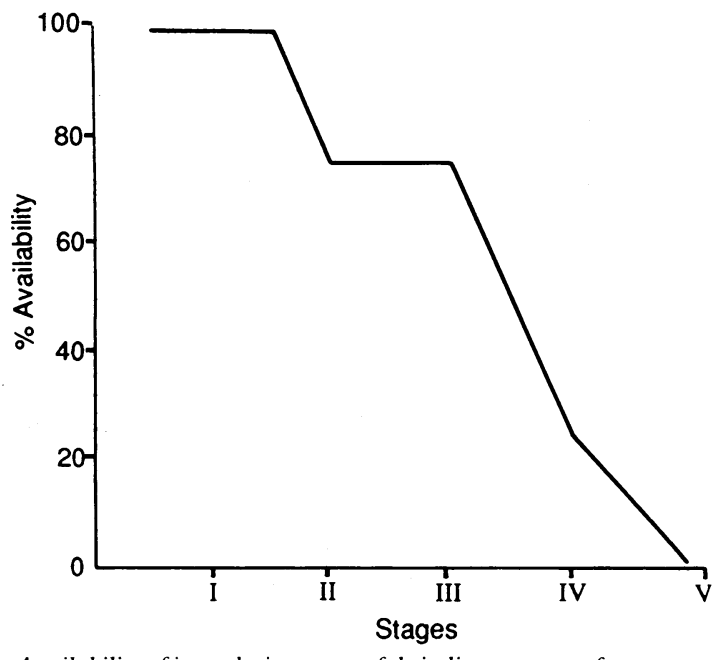

Availability of items during stages of their disappearance from general commodity circulation

item is totally missing from the GCC. One can go all around the city including the outskirts for a whole day, but the possibility of an absolute negative result is extremely high $(\mathrm{p}<0.000001)$. The general signs of the disappearance of many items could be summarised as: no queue; empty shelves or shelves containing one inedible item; absence of sales people; and an extremely unpleasant smell of something in the process of decomposition.

The consequence of the events described above is shown in the figure, which was drawn on the basis of randomised observation. The final stage was not reached for all items during the observation period, but every day stage I is applied to something new, initiating the sequence. The table shows the stages in the cycle reached at September 1990 by items chosen at random.

\section{Discussion}

In this study an attempt has been made to describe the natural history of the disappearance of various products of agriculture and industry from the consumer market. The laws derived therefrom can be applied in various forms to any commodity or service, including medicines or places in hospitals, during this most exciting time known in world literature as "perestroika" (see M Gorbachev in Pravada, April 1985 to present). Owing to limited space we are not able to show here the side effects of the events described, or to foresee them. One obvious consequence of all this is a sharp rise in prices on the black market, coupled with a tendency to sell only for hard currency. This especially concerns durable goods, the prices for which rise in such a way that a used car costs three times more than it did when it was new a few years ago (the "violin law" discovered by $\mathrm{J}$ Guralsky in the '50s; personal communication). The discussions going on in the press and in parliament have only reached the stage of programmes for the future. In the meantime the gap between word and deed is growing dramatically. The state of the economy is such that, as an Izvestia correspondent wrote recently in a article entitled "A Line for Bread" (13 September 1990). "We should not be surprised when something disappears. We should be surprised that something is still on sale."

It is especially fascinating to see the very latest development on Soviet television-Western commercials advertising foodstuffs and goods the average Soviet person has never seen or heard of.

I thank my wife, Mrs A Falkowski, who provided many of the observations noted here and actually took part in all physical activities directed toward keeping the household going. The statistical analysis (stage II) was done by her while standing in queues. 